\title{
Grains of Wisdom: Transgenic Rice for Oral Allergen Immunotherapy in Japanese Cedar Pollen-Allergic Patients
}

\author{
Carla Irani $^{\mathrm{a}}$ Angela Haczku ${ }^{\mathrm{b}}$ \\ anternal Medicine and Clinical Immunology, Saint Joseph University, Beirut, Lebanon; ${ }^{b}$ Department of Internal \\ Medicine, UC Davis Lung Center, University of California, Davis, CA, USA
}

Allergen-specific immunotherapy (AIT) has been considered to date the only disease-modifying treatment in allergic rhinitis. In this issue of International Archives of Allergy and Immunology (IAAI), Endo et al. [1] report the first use of transgenic rice to deliver high doses of allergen for oral immunotherapy of Japanese cedar allergic rhinitis patients. Vaccine development is among the greatest achievements in the history of medicine. The goal of immunotherapy by vaccine is to harness broad and specific immune responses involving $\mathrm{B}$ - and/or Tcells depending on the approach. In AIT, administration of allergenic preparations aims to restore tolerance and reduce allergic symptoms. AIT can be delivered intramuscularly, subcutaneously, sublingually, orally, or intralymphatically with increasing doses as the patient's tolerance grows over time [2]. AIT has been used to treat IgE-mediated allergic diseases since the early 1900s [3], but it still remains fraught with problems. For example, optimal dosing, length, different up-dosing regiments, improving adherence and management of polyallergies in patients, and the comparative efficacy of various adjuvants and routes of administration are continuously discussed [4]. The danger of anaphylaxis occurring during the administration of AIT also remains high. When successful however, AIT treats and prevents the development of allergic asthma, rhinitis, and venom-induced

karger@karger.com

(C) 2020 S. Karger AG, Basel

www.karger.com/iaa

Karger anaphylaxis, and was demonstrated to prevent sensitization with new allergens for up to 12 years $[5,6]$. In fact AIT has been considered the only disease-modifying treatment in allergic rhinitis [7]. Therefore, the quest to develop safer and more effective AIT continues today.

In an allergen-triggered immediate reaction, B-cellsecreted IgE activates mast cells and basophils. Allergenspecific T-helper type 2 (Th2) cells are also activated, leading to a delayed and prolonged inflammatory reaction. AIT induces an increased number and activation of allergen-specific $\mathrm{CD} 4+\mathrm{CD} 25+$ regulatory T-cells [8] that produce IL-10, an immunosuppressive cytokine, thereby attaining immune tolerance. Since the discovery of its principle in 1911, several approaches to immunotherapy have been tested. One of the most recent ones is to use allergenic T-cell epitope peptides. The first successful immunotherapy that used T-cell epitope peptides of bee venom phospholipase A2 was shown to induce specific $\mathrm{T}$-cell anergy and tolerance to bee venom in allergic patients [9]. Peptide AIT approaches appear to be efficacious, often shorter than the classical methods and also safer, because T-cell epitopes do not cross-link cell-bound IgE, eliminating the risk of anaphylaxis.

Edited by: H.-U. Simon, Bern. 
Oral administration of allergens for immunotherapy could be achieved using plants, especially rice seeds, recognized as superior allergen carriers because of their high productivity, stability, and safety. Transgenic rice seeds in which major epitopes of cedar pollen allergens or house dust mites are expressed have been recently developed [10]. The most common allergen responsible for allergic rhinitis in Japan is Japanese cedar (Cryptomeria japonica) pollinosis, [11]. Takaishi et al. [12, 13] recently developed transgenic rice that expresses all possible $\mathrm{T}$-cell epitope repertoires of Cry j 1 and Cry j 2, the molecular determinants of Japanese cedar. They showed that allergen-sensitized mice that ate transgenic rice daily for 3 weeks had a marked suppression of allergen-specific CD4+ T-cell proliferation, IgE and IgG levels compared with mice fed non-transgenic rice, in response to challenge with crude C. japonica pollen allergen.

In this issue of IAAI, Endo et al. [1] present a study on the T-cell peptide mucosal route of immunotherapy for cedar pollinosis patients. They used transgenic rice expressing 7 overlapping epitope T-cell peptides (7Crp) to deliver a high dose of allergen for specific T-cell tolerance induction. Allergen-specific T-cell proliferation against Japanese cedar pollen allergens, Cry j 1 and Cry j 2, were significantly downregulated by this treatment. The suppressive effect of transgenic rice on allergen-specific Tcell proliferation was dose dependent, appeared within 2 weeks, and remained during the pollen season. However, T-cell tolerogenicity such as IL-10 upregulation and IL13 downregulation was not associated with either decreased cedar pollen-specific IgE antibodies, or increased IgG blocking antibodies upon 20 weeks of transgenic rice intake. There was no effect on the IFN- $\gamma$ and IL-5 secretions from Th1 and Th2 cells and the effect on IL- 4 was also minimal, in contrast to what was seen in previous peptide AIT studies [14]. This treatment did not accomplish improvement of clinical symptoms (as measured by the Japanese rhinitis quality of life score or the total nasal symptom and medication scores) either. The effect on improving of symptom score was only significant for nasal and eyes itching without significant improvement on the rest of nasal symptoms. Thus, even though T-cell proliferative activities to Cry $\mathrm{j} 1$ and Cry $\mathrm{j} 2$ were highly suppressed, 20 weeks of transgenic rice consumption did not show a profound clinical improvement.

The authors speculate that the partial effects seen may be due to the possibility that 7Crp does not cover the full repertoire of T-cell epitopes localized in Cry $\mathrm{j} 1$ and Cry $\mathrm{j}$ 2 molecules due to the diversity of MHC (HLA) class II alleles in patients. Although $92 \%$ of Japanese cedar pol- linosis patients are covered by 7Crp, some Cry $\mathrm{j} 1$ - and Cry j 2-specific T-cells that are not suppressed by the 7Crp peptide may proliferate in some patients during the pollen season. Furthermore, it might take a longer course (more than 2 seasons) to accomplish full tolerance and improve clinical symptoms. Thus, inclusion of additional T-cell epitopes to address MHC diversity and a more prolonged preseasonal treatment and longer-term treatment may be necessary to accomplish significant clinical improvement.

Nonetheless, it is important to distinguish this study as it is the first clinical trial to administer transgenic rice to human subjects exploring the T-cell epitope peptides as a future mode of allergen immunotherapy. Peptide immunotherapy is safe due to a lack of IgE crosslinking and minimal inflammatory potential. Indeed, with administration of different doses of transgenic rice containing the 7Crp peptide to human subjects (with or without Japanese cedar allergy), no adverse effects including immediate or late-phase allergic reactions were observed. This is a major improvement over previous reports of T-cell-mediated late-phase side effects for birch pollen and cat peptide vaccines [15].

In conclusion, while allergen immunotherapy is still being explored by different mechanistic approaches, the study by Endo et al. [1] supports a potential future for an effective and safer mucosal route of T-cell peptide immunotherapy with transgenic rice technology. Because of its potential impact on the improvement of quality of life in allergic disease, AIT will certainly stay a present and future therapy for respiratory and food allergies. Larger clinical studies are needed to reliably assess the added benefit for the patient of using transgenic rice for delivering peptide allergens for AIT.

\section{Conflict of Interest Statement}

The authors have no conflicts of interest to declare.

\section{Funding Sources}

Funding was obtained through NIH grant No. 2R42AI132012 to A.H.

\section{Author Contributions}

C.I. drafted the manuscript and A.H. edited and finalized it. 


\section{References}

1 Endo T, Asaka D, Nakayama T, Saito S, Kodama $\mathrm{H}$, Mitsuyoshi $\mathrm{R}$, et al. Immunological and symptomatic effects of oral intake of transgenic rice containing seven linked major $\mathrm{T}$ cell epitopes from Japanese cedar pollen allergens. Int Arch Allergy Immunol. 2020. doi: 10.1159/000509996.

2 Calderon MA, Waserman S, Bernstein DI, Demoly P, Douglass J, Gagnon R, et al. Clinical Practice of Allergen Immunotherapy for Allergic Rhinoconjunctivitis and Asthma: An Expert Panel Report. J Allergy Clin Immunol Pract. 2020 Oct;8(9):2920-2936.e1.

3 Curtis HH. The immunizing cure of hay fever. Med Newsl. 1900 Jul;1900:77.

4 Nelson HS. Allergy immunotherapy for inhalant allergens: strategies to improve efficacy. Allergy Asthma Proc. 2020 Jan;41(1):2637.

5 Burks AW, Calderon MA, Casale T, Cox L, Demoly P, Jutel M, et al. Update on allergy immunotherapy: American Academy of Allergy, Asthma \& Immunology/European Academy of Allergy and Clinical Immunology/PRACTALL consensus report. J Allergy Clin Immunol. 2013 May;131(5):1288-96.e3.
6 Calderón MA, Casale T, Cox L, Akdis CA, Burks AW, Nelson HS, et al. Allergen immunotherapy: a new semantic framework from the European Academy of Allergy and Clinical Immunology/American Academy of $\mathrm{Al}$ lergy, Asthma and Immunology/PRACTALL consensus report. Allergy. $2013 \mathrm{Jul} ; 68(7)$ : 825-8.

7 Bousquet J, Lockey R, Malling HJ. Allergen immunotherapy: therapeutic vaccines for allergic diseases. A WHO position paper. J Allergy Clin Immunol. 1998 Oct;102(4 Pt 1): $558-62$.

8 Robinson DS, Larché M, Durham SR. Tregs and allergic disease. J Clin Invest. 2004 Nov; 114(10):1389-97.

9 Müller U, Akdis CA, Fricker M, Akdis M, Blesken T, Bettens F, et al. Successful immunotherapy with T-cell epitope peptides of bee venom phospholipase A2 induces specific Tcell anergy in patients allergic to bee venom. J Allergy Clin Immunol. 1998 Jun;101(6 Pt 1): $747-54$.
10 Saeki M, Nishimura T, Kaminuma O, Mori A, Hiroi T. Oral immunotherapy for allergic diseases using transgenic rice seeds: current state and future prospects. Int Arch Allergy Immunol. 2013;161(s2 Suppl 2):164-9.

11 Morii W, Sakai A, Ninomiya T, Kidoguchi M, Sumazaki R, Fujieda S, et al. Association of Japanese cedar pollinosis and sensitization with HLA-DPB1 in the Japanese adolescent. Allergol Int. 2018 Jan;67(1):61-6.

12 Takaishi S, Saito S, Endo T, Asaka D, Wakasa $\mathrm{Y}$, Takagi H, et al. T-cell activation by transgenic rice seeds expressing the genetically modified Japanese cedar pollen allergens. Immunology. 2019 Oct;158(2):94-103.

13 Takaishi S, Saito S, Kamada M, Otori N, Kojima H, Ozawa K, et al. Evaluation of basophil activation caused by transgenic rice seeds expressing whole $\mathrm{T}$ cell epitopes of the major Japanese cedar pollen allergens. Clin Transl Allergy. 2019 Feb;9(1):11.

14 Prickett SR, Rolland JM, O'Hehir RE. Immunoregulatory $\mathrm{T}$ cell epitope peptides: the new frontier in allergy therapy. Clin Exp Allergy. 2015 Jun;45(6):1015-26.

15 Satitsuksanoa P, Głobińska A, Jansen K, van de Veen W, Akdis M. Modified allergens for immunotherapy. Curr Allergy Asthma Rep. 2018 Feb;18(2):9. 